\title{
Determination of Preferred pH for Root-knot Nematode Aggregation Using Pluronic F-127 Gel
}

\author{
Congli Wang • George Bruening • \\ Valerie M. Williamson
}

Received: 7 July 2009 /Revised: 15 September 2009 /Accepted: 30 September 2009 / Published online: 20 October 2009

(C) The Author(s) 2009. This article is published with open access at Springerlink.com

\begin{abstract}
Root-knot nematodes (Meloidogyne spp.) are obligate endoparasites of a wide range of plant species. The infective stage is attracted strongly to and enters host roots at the zone of elongation, but the compounds responsible for this attraction have not been identified. We developed a simple assay to investigate nematode response to chemical gradients that uses Pluronic F-127, a synthetic block copolymer that, as a $23 \%$ aqueous solution, forms a liquid at low temperature and a gel at room temperature. Test chemicals are put into a modified pipette tip, or 'chemical dispenser,' and dispensers are inserted into the gel in which nematodes have been dispersed. Meloidogyne hapla is attracted to $\mathrm{pH}$ gradients formed by acetic acid and several other Brønsted acids and aggregates between $\mathrm{pH}$ 4.5 and 5.4. While this $\mathrm{pH}$ range was attractive to all tested root-knot nematode strains and species, the level of aggregation depended on the species/strain assessed. For actively growing roots, the $\mathrm{pH}$ at the root surface is most acidic at the zone of elongation. This observation is consistent with the idea that low $\mathrm{pH}$ is an attractant for nematodes. Root-knot nematodes have been reported to be attracted to carbon dioxide, but our experiments suggest that the observed attraction may be due to acidification of solutions by dissolved $\mathrm{CO}_{2}$ rather than to $\mathrm{CO}_{2}$ itself. These results suggest that Pluronic F-127 gel will be broadly applicable for examining responses of a range of organisms to chemical gradients or to each other.
\end{abstract}

C. Wang $\cdot$ V. M. Williamson $(\bowtie)$

Department of Nematology, University of California,

Davis, CA 95616, USA

e-mail: vmwilliamson@ucdavis.edu

G. Bruening

Department of Plant Pathology, University of California,

Davis, CA 95616, USA
Keywords Nematode $\cdot$ Chemotaxis · Carbon dioxide . Gradient $\cdot$ Meloidogyne hapla $\cdot$ Meloidogyne incognita . Meloidogyne javanica $\cdot$ Bioassay

\section{Introduction}

Root-knot nematodes (RKNs) (Meloidogyne spp.) are destructive pathogens of agricultural crops. The infective stage, the second stage juvenile (J2), is attracted to host roots, especially the zone of elongation of growing roots, and migrates by sinusoidal movements toward roots, presumably due to a concentration gradient of a substance or substances from the root (Linford 1939; Wyss et al. 1992; Wang et al. 2009). Disrupting host-finding behavior may be an effective way of controlling plant-parasitic nematodes. However, little is known about the chemical signals that the nematode perceives from the root. Several assays have been used to study chemotaxis in nematodes, but all have limitations (Spence et al. 2008). Many assays have used agarose plates (e.g., Ward 1973; Riddle and Bird 1985); however, nematodes move along the surface of the agar in a film of water, and thus, the assay is 2-dimensional. Nematodes move on their sides on agar surfaces and perceive chemicals through amphids (anterior chemoreceptors). They detect chemical gradients by side-to-side (up and down on agar surfaces) displacement of the amphids due to head movements (Ward 1973). Other attraction assays have used sand-filled tubes in which movement of nematodes cannot be observed directly (Robinson 1995).

Arguably the most frequently suggested attractant for plant parasitic nematodes has been carbon dioxide (Klingler 1965; Prot 1980; Pline and Dusenbery 1987; Robinson 1995). Perry (2005) suggested that $\mathrm{CO}_{2}$ was a long distance attractant, and that local attraction was due to gradients of 
other signals such as $\mathrm{pH}$. However, the diversity of sources of $\mathrm{CO}_{2}$ in the rhizosphere and the imperfect correlation between regions of the root with high $\mathrm{CO}_{2}$ and those with highest attraction suggest that $\mathrm{CO}_{2}$ may not be a specific signal (Bird 1960). In the soil, $\mathrm{CO}_{2}$ efflux is the result of root and rhizospheric respiration and organic matter decomposition. Meloidogyne incognita is repelled by ammonia and several nitrogenous salts released from decaying material (Castro et al. 1991) possibly further modulating its response. For the free-living nematode Caenorhabditis elegans, $\mathrm{CO}_{2}$ has been described both as an attractant and a repellant (Dusenbery 1983; Bretscher et al. 2008; Hallem and Sternberg 2008). Recent studies with $C$. elegans suggest that the degree of $\mathrm{CO}_{2}$ avoidance depends on strain and nutritional status (Hallem and Sternberg 2008).

Pluronic F-127 (PF-127) has been used by our group to study plant-nematode interactions and nematode behavior (Wang et al. 2009). A 23\% PF-127 solution forms a semisolid gel at room temperature but is liquid at $15^{\circ} \mathrm{C}$ and below. The gel is highly transparent and generally has low toxicity or is non-toxic, depending on the organism and gel concentration used (Gardener and Jones 1984; Ko and Van Gundy 1988). Nematodes can be mixed in PF-127 solution at $15^{\circ} \mathrm{C}$. As the solution warms to room temperature, nematodes become suspended in the gel. They can move freely in 3 dimensions through the gel, allowing examination of behavior in response to various treatments. Nematodes dispersed in PF-127 gel are highly attracted to roots, aggregating mainly at the zone of elongation (Wang et al. 2009). In the absence of roots, nematodes aggregate into tight balls containing most of the nematodes that were distributed in PF-127 gel. We have postulated that this aggregation is due to a preference for low oxygen concentration, a response to anhydrobiotic stress, and/or inter-nematode chemical signals (pheromones). The ability to form aggregates differs among RKN species and strains (Wang et al. 2009; Wang and Williamson, unpublished).

Here, we tested the utility of PF-127 gels for examining root-knot nematode movement in gradients of $\mathrm{pH}$ and $\mathrm{CO}_{2}$. Because the genetic map and genome sequence for Meloidogyne hapla strain VW9 are available (Opperman et al. 2008), thus opening the potential to explore genes involved in signal recognition and behavior by the nematode, we focused on this nematode in the current work. We have, however, compared the behavior to isolates of other agronomically important species, including $M$. incognita, for which the genome sequence is also available (Abad et al. 2008).

\section{Methods and Materials}

Nematodes and Materials Meloidogyne hapla strains used were VW9 (Liu and Williamson 2006), NCS (from C.
Opperman, North Carolina State University) and LM (from P. Roberts, University of California, Riverside; Chen and Roberts 2003). M. javanica strains VW4 and VW5 are a pair of nearly isogenic strains that differ in ability to reproduce on tomato bearing the resistance gene $\mathrm{Mi}-1$ (Gleason et al. 2008). M. incognita strains used were 557R (Yaghoobi et al. 2005), W1(inbred from nematodes isolated from a Woodland, CA tomato field), Beltran (P. Roberts), Harmony (H. Ferris, University of California, Davis), and VW6 (inbred from a field isolate obtained by H. Ferris). All M. hapla strains, M. javanica strain VW5, and M. incognita strains $557 \mathrm{R}$ and W1 were maintained on tomato cultivar VFNT, which carries the gene $M i-1$. The remaining strains were maintained on the nematode-susceptible tomato cultivar UC82. Eggs were collected and axenic J2s produced as described by Branch et al. (2004) with minor modifications (Wang et al. 2009), then rinsed four times with sterile water; larvae hatched at room temperature.

Methanesulfonic acid and pyridine, both $99 \%$, were from Acros Organics (Geel, Belgium). Bromocresol purple was the sodium salt from National Analine Division, New York, NY, U.S.A.. Other chemicals were A.C.S. grade.

Gel Preparation and Attraction Assay PF-127 (Sigma, St. Louis, MO, U.S.A.) solution was $23 \% \mathrm{w} / \mathrm{v}$ in $10 \mathrm{mM}$ Tris, $10 \mathrm{mM}$ morpholino-ethanesulfonic acid (MES), $\mathrm{pH}$ 7.1, unless otherwise indicated. Suspended PF-127 was dissolved by stirring for $24 \mathrm{~h}$ at $4^{\circ} \mathrm{C}$ (Wang et al. 2009). Where noted, the $\mathrm{pH}$ indicator bromocresol purple was included. The solution was stored at $15^{\circ} \mathrm{C}$. Twenty $\mathrm{ml}$ of PF-127 solution containing freshly-hatched J2 (6000 J2 per plate unless otherwise indicated) were poured into each Petri dish (nominal $100 \times 15 \mathrm{~mm}$ ) at $15^{\circ} \mathrm{C}$.

"Chemical dispensers" were prepared by cutting standard $5 \mathrm{~cm}, 200 \mu \mathrm{l}$ pipette tips (USA Scientific Inc.) $5 \mathrm{~mm}$ from the small end and $20 \mathrm{~mm}$ from the large end. The test chemical solutions were prepared in 23\% PF-127 and maintained on ice. Approximately $100 \mu 1$ of the test solution were pipetted into each chemical dispenser, which was held horizontally while the solution was allowed to gel at room temperature. The Petri dish with the PF-127 solution and dispersed nematodes was placed at room temperature, and two dispensers were placed anti-parallel with ends not closer than $3 \mathrm{~cm}$ from the Petri plate edge, before the gel formed and before bubbles could develop at the dispenser ends. Dispensers rested on the bottom of the plate, and the top of the large opening of the dispenser was approximately at the surface of the gel in the Petri dish when $20 \mathrm{ml}$ of PF127 solution were used (i.e., $3.4 \mathrm{~mm}$ deep gel). At the indicated time after initiation of the assay, the number of nematodes was counted within the $5 \mathrm{~mm}$ diam. circle centered at the small end of pipette tip. Control dispensers containing 23\% PF-127 in water were used as checks. The 
different sizes of the two dispenser openings allowed us to examine two different concentration gradients simultaneously, and the paired dispensers in each plate provided duplicate analyses. At least three plates were included in each experiment, and each experiment was repeated at least twice. Micrographs were captured with a Nikon SMZ-U dissecting microscope by using SimplePCI High Performance Imaging System (Compix Inc, Sewickley, PA, USA). To obtain a broader view of the nematode distribution patterns in response to chemical gradients, lower magnification photographs of Petri plates were taken with a digital camera by using edge lighting and against a black background.

$p H$ Measurements The $\mathrm{pH}$ in gels was measured with a $\mathrm{pH}$ Meter (Denver Instrument Company, Arvada, CO, USA), by direct insertion into gel of a PHR-146 Micro Combination $\mathrm{pH}$ electrode (Lazar Research Laboratories, Inc., Los Angeles, CA, USA). $\mathrm{pH}$ meter calibration was performed by the two point standardization method $(\mathrm{pH} 7$ and $\mathrm{pH} 4)$ according to the manufacturer's instructions. $\mathrm{pH}$ measurements were repeated at least twice.

Carbon Dioxide Delivery Assay A Petri dish lid was modified for delivery of $\mathrm{CO}_{2}$ to PF-127 gel (Fig. 1). $\mathrm{CO}_{2}$ sublimed from dry ice in a container was passed via tubing through water and delivered to a central $1.5 \mathrm{~cm}$ diam. circle on the gel surface. Water-saturated air was delivered to the remainder of the gel (Fig. 1), thus creating a concentric gradient of $\mathrm{CO}_{2}$ in air in the gel from the $1.5 \mathrm{~cm}$ circle to the edge of the plate.

Statistical Analysis JMP software (SAS Institute Inc., Cary, NC, USA) was used for statistical analyses. Data were subjected to one-way analysis of variance (one wayANOVA). Results are reported as significant or nonsignificant in Tukey's Honestly Significant Difference (Tukey HSD) Test $(P<0.05)$. a

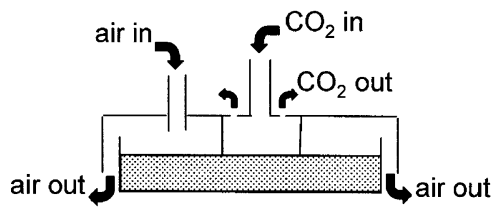

b

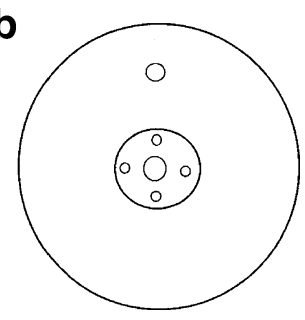

Fig. 1 Apparatus for $\mathrm{CO}_{2}$ delivery to $\mathrm{PF}-127$ gel. The lid of a standard Petri dish was modified with entry and exit ports for $\mathrm{CO}_{2}$, and an entry port for air. Air could escape under the edge of the lid. An acrylic cylinder cemented under the lid just touched gel surface to maintain an area of water-saturated $\mathrm{CO}_{2}$ on the gel surface. The apparatus is shown in cross section (A) and top view (B). The stippled region in A represents the gel with the nematodes

\section{Results}

Formation of $p H$ Gradients in Gel To assess gradient formation in PF-127 gel, the $\mathrm{pH}$ indicator bromocresol purple was incorporated into gel in $10 \mathrm{mM}$ Tris-MES buffer, $\mathrm{pH}$ 7.1. Two dispensers with $0.17 \mathrm{M}$ acetic acid were placed into each plate. After $4 \mathrm{~h}$, yellow circles were seen around the openings of the dispenser, indicating that proton diffusion occurred in a radial pattern from the openings of the dispenser. The size of the circles increased slowly over the next $20 \mathrm{~h}$ (Fig. 2).

Aggregation of M. hapla (Strain VW9) in pH Gradients The response of M. hapla strain VW9 J2 was monitored in $\mathrm{pH}$ gradients produced around the ends of dispensers that had been charged with $0.17,0.34$, or $0.85 \mathrm{M}$ acetic acid. Nematode clustering was observed at the dispenser small end $3 \mathrm{~h}$ (not shown) after insertion and was maintained after 5 and $24 \mathrm{~h}$ (Fig. 3A and B, respectively). Five h after insertion, the gradient near the dispenser large end extended over a sufficient gel volume so that $\mathrm{J} 2$ responded by congregating into a halo (Fig. $3 \mathrm{C}, 0.34 \mathrm{M}$, and $0.85 \mathrm{M}$ acetic acid dispensers). Presumably, the halo was generated because $\mathrm{J} 2$ prefer a specific low $\mathrm{pH}$ range to the even lower $\mathrm{pH}$ near the dispenser end and the $\mathrm{pH} 7.1$ of the PF-127 gel in which $\mathrm{J} 2$ were originally suspended. Figure 4 presents J2 density related to distance from the dispenser large end for $0.34 \mathrm{M}$ and $1.7 \mathrm{M}$ acetic acid. The observed distributions conformed to a normal curve, and the gradient created by $0.34 \mathrm{M}$ acetic acid stimulated $\mathrm{J} 2$ to achieve a density ten times greater than the initial density of $\mathrm{J} 2$ in the gel at the most dense part of the halo (Fig. 4).

By using a microelectrode, $\mathrm{pH}$ was measured at the boundaries of the halo of high nematode density. For both low $\mathrm{pH}$ and high $\mathrm{pH}$ boundaries, more than 50 readings were made from three plates. At $7 \mathrm{~h}$ after assay initiation, the $\mathrm{pH}$ was $4.54 \pm 0.05$ for the inner boundary and $5.40 \pm$ 0.15 for the outer boundary. At $20 \mathrm{~h}$ after assay initiation, the circle was larger, but the $\mathrm{pH}$ values at the boundaries were similar $(\mathrm{pH} 4.58 \pm 0.17$ for inner boundary and $\mathrm{pH}$ $5.37 \pm 0.13$ for outer boundary). The experiment was repeated, and the same boundary $\mathrm{pH}$ values were obtained. No aggregation of nematodes was observed with any of the checks that contained dispensers with $23 \%$ PF-127 in water (not shown).

To test whether acetate from ionized acetic acid was sufficient to account for gradient-directed nematode migration, the response of $M$. hapla $\mathrm{J} 2$ was observed for dispensers with 10 and $50 \mathrm{mM}$ sodium acetate, corresponding to the range of acetate ion expected in the previously tested acetic acid-loaded dispensers. At $24 \mathrm{~h}$, no nematode aggregation was seen at the openings of the dispensers (results not shown), suggesting that protons or 

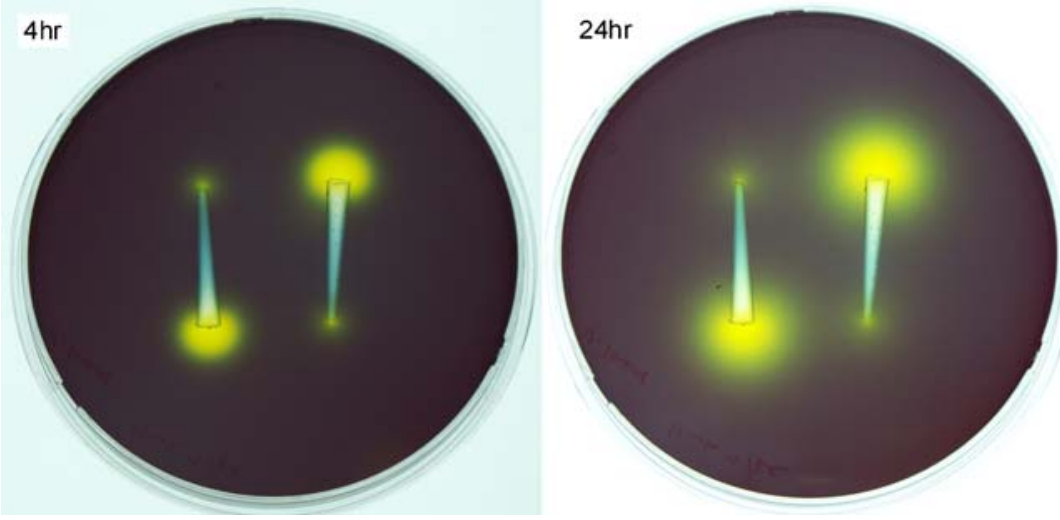

Fig. $2 \mathrm{pH}$ gradient formation in PF-127 gel. The pH indicator bromocresol purple (pH 5.2-6.8, yellow to purple) was included in the gel. The dispensers initially contained $0.17 \mathrm{M}$ acetic acid, and plates are shown 4 and $24 \mathrm{~h}$ after the dispenser was inserted into the gel

acetic acid rather than acetate ions affected the nematode aggregation.

By using the dispenser system, we tested the response of VW9 to a variety of Brønsted (proton-donating) acids, including strong acids $\left(\mathrm{HCl}, \mathrm{H}_{2} \mathrm{SO}_{4}, \mathrm{HClO}_{4}\right.$, methanesulfonic acid), carboxylic acids (acetic, citric, formic, lactic, propionic, and succinic), pyridinium hydrochloride, and pyridinium methanesulfonate. Strong acids and three
$170 \mathrm{mM} \mathrm{HAc}$
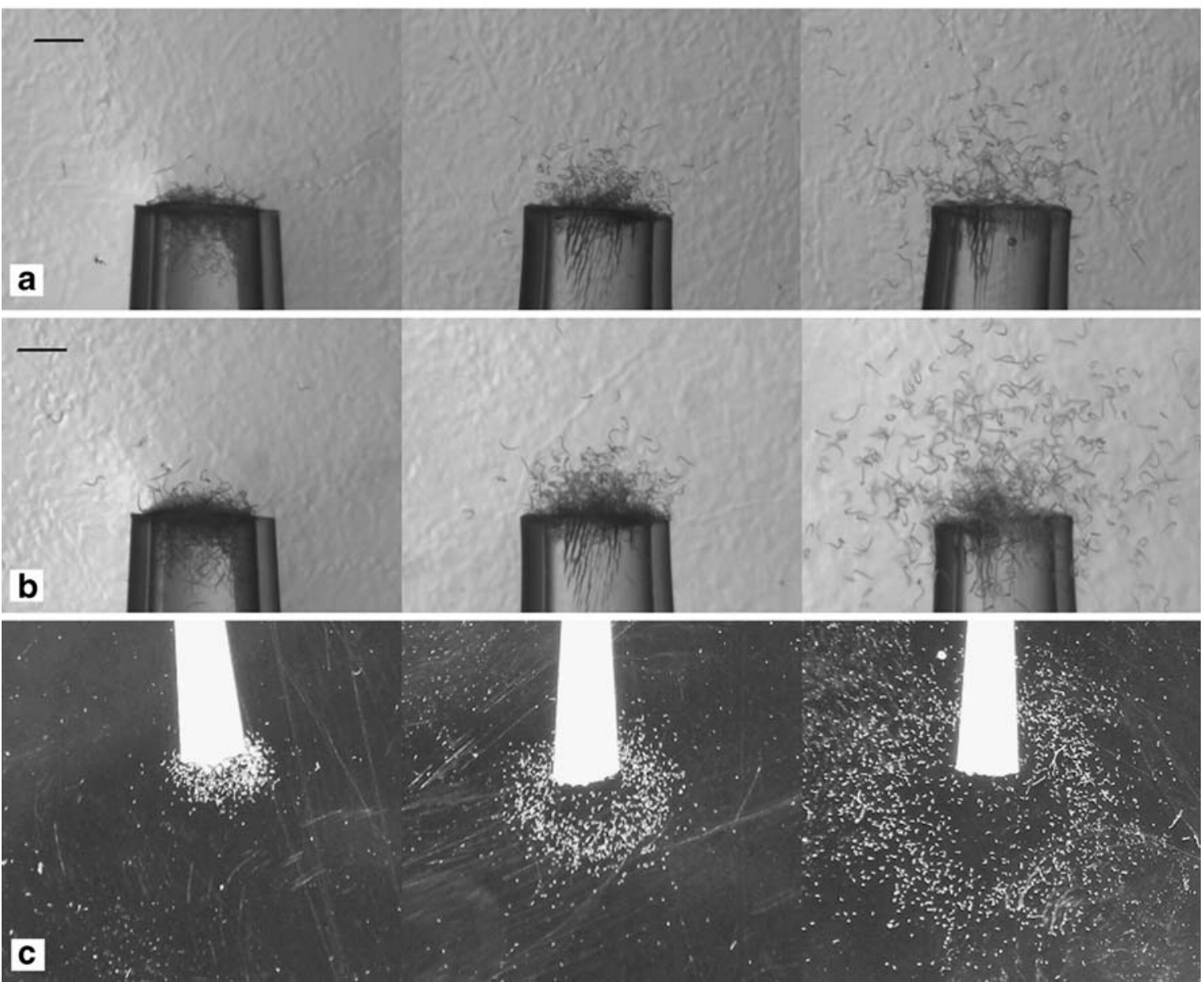

Fig. 3 Migration of Meloidogyne hapla VW9 J2 in acetic acid gradients in PF-127 gel. Dispensers contain $0.17 \mathrm{M}, 0.34 \mathrm{M}$, or $0.85 \mathrm{M}$ acetic acid as indicated at the top of the three columns of images. Dissecting microscope images of the dispenser small end were recorded at $5 \mathrm{~h} \mathrm{(A)}$ and $24 \mathrm{~h}(\mathbf{B})$ after inserting dispensers in the gel. Scale bar $=1 \mathrm{~mm}$. Lower magnification edge-lighted photographs of the dispenser large end at $24 \mathrm{~h}$ is shown in $\mathrm{C}$. The diameter of the large end of the dispenser is $\sim 4 \mathrm{~mm}$ 


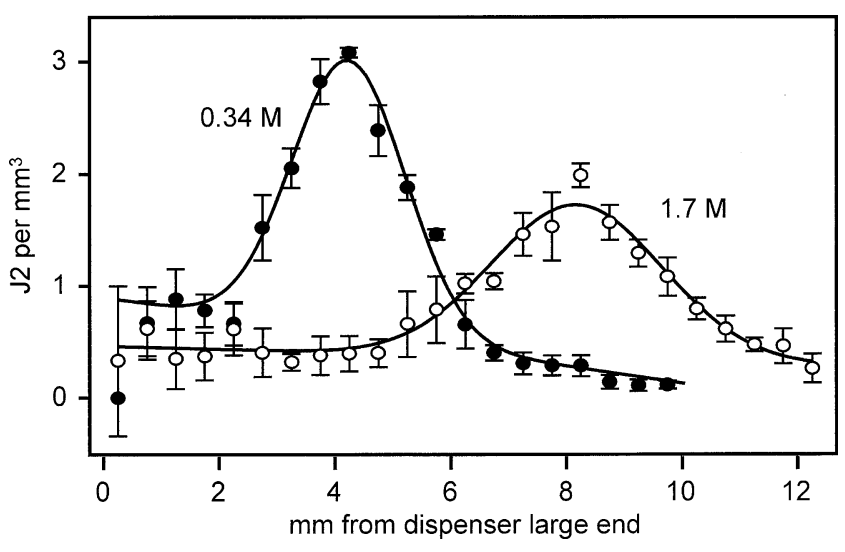

Fig. 4 Distribution of VW9 J2 in acetic acid gradients. Dispensers containing acetic acid in 23\% PF-127 gel were immersed in buffered PF-127 gel containing $0.30 \mathrm{~J} 2$ per $\mathrm{mm}^{3}$. After $5 \mathrm{~h}$, the gel was photographed with edge lighting. Ninety degree arcs, scaled to $0.5 \mathrm{~mm}$ wide in the original gel, were superimposed on the enlarged photographic images with the origin of the arcs at the middle of the dispenser wide end. J2 within each arc were counted for the $0.34 \mathrm{M}$ $(\bullet)$ and $1.7 \mathrm{M}(\circ)$ acetic acid dispensers (four dispensers from three plates), and the data were transformed to $\mathrm{J} 2$ per $\mathrm{mm}^{3}$ of gel. The average values and standard deviations are presented against distance from the dispenser large end. The standard deviation expanded at small distances from the dispenser because of the small volumes corresponding to the short arcs. Data were fit to Gaussian curves by a least-squares method

monoprotic carboxylic acids (acetic, formic, and propionic acids) induced movement of the nematodes to form a halo centered at the wide opening of the dispenser (Figs. 3C and $5 \mathrm{~A}-\mathrm{C}$ ) and aggregation at the small opening (Figs. 3A\&B, and $5 \mathrm{G}$ ). For lactic, citric, and succinic acids, the J2 migrated to and aggregated inside the dispensers (for example, see Fig. 5E and H). The ability of citric acid and citrates to act as a $\mathrm{J} 2$ attractant was tested by charging dispensers with $0.40 \mathrm{M}$ citrate plus citric acid buffers at $\mathrm{pH} \sim 4.5$ or $\sim 5.5$ (corresponding the observed $\mathrm{pH}$ values at the halo edges) and with sodium, potassium, ethanolammonium, or diethanolammonium as the cation. All of these citrate buffers, like citric acid itself, attracted $\mathrm{J} 2$ well into the dispensers, rather than just to the openings, suggesting that citrate/citric acid attracted J2 sufficiently to overcome any tendency to form a halo in a citric acid gradient (results not shown). Pyridinium ions were selected as another Brønsted acid because of the similarity of the $\mathrm{pK}_{\mathrm{a}}$ (5.2) to that of acetic acid (4.8). Pyridinium methosulfonate (Fig. 5E) and pyridinium chloride (not shown) also caused aggregation of $\mathrm{J} 2$ inside the tip in a manner similar to that seen for citric acid.

Root-knot Nematode Species and/or Strains Differ in Responsiveness to Acetic Acid Different species and strains of root-knot nematodes differ in the rate at which they aggregated at root tips in PF-127 gel (Wang et al. 2009). Responses of different RKN species and strains to acetic acid gradients were compared $3 \mathrm{~h}$ after initiation of the assay (Table 1). Meloidogyne hapla strain VW9 had the highest aggregation at the dispenser tip of all the RKN strains tested. The nearly isogenic $M$. javanica strains VW4 and VW5, which differ in their ability to parasitize tomato with the resistance gene $M i-1$, did not show significant differences in attraction to acetic acid. However, significant differences were seen among $M$. incognita strains derived from isolates originating from different locations and different hosts. Strains VW6, Beltran and W1 aggregated significantly less than $M$. incognita strain 577R. M. incognita strain Harmony, which was originally isolated from grape, aggregated much more slowly than the other strains. By $24 \mathrm{~h}$ and for several species and strains, the number of nematodes near the dispenser tip was too great to count with confidence, and was scored as described in Fig. 6. However, even for strain Harmony, the number of nematodes at the tip increased between 3 and $24 \mathrm{~h}$, and the relative aggregation of the different strains remained the same (Table 1). The $\mathrm{pH}$ range of maximum aggregation was assessed at $24 \mathrm{~h}$ by using a microelectrode, and all were found to aggregate between $\mathrm{pH} 4.5$ and 5.4. Thus, it did not appear that the strains differed in the $\mathrm{pH}$ range to which they were attracted, but they did differ in the rate at which they congregated in the gel region of that $\mathrm{pH}$ range.

Response of Nematodes to $\mathrm{Gel}$ Exposed to $\mathrm{CO}_{2}$ To investigate $\mathrm{RKN} \mathrm{J} 2$ response to $\mathrm{CO}_{2}$, we delivered $\mathrm{CO}_{2}$ to a $1.5 \mathrm{~cm}$ circle in the center of a PF-127 gel plate buffered with $10 \mathrm{mM}$ Tris-MES, $\mathrm{pH} 7.1$, in which $\mathrm{J} 2$ of M. hapla VW9 were distributed evenly. In a parallel experiment, $\mathrm{CO}_{2}$ was delivered to a plate with the same gel, but without nematodes and with the $\mathrm{pH}$ indicator bromocresol purple. By two hours, the region of the gel exposed to $\mathrm{CO}_{2}$ had acidified sufficiently to turn the indicator yellow (i.e., $\mathrm{pH}$ 5.2 or less), and nematodes began to aggregate outside the border of the circle. At $24 \mathrm{~h}$, the yellow area remained limited to the circle area exposed to $\mathrm{CO}_{2}$ with a gradient to blue in the $3 \mathrm{~mm}$ just outside the circle. Nematodes aggregated outside the circle area (Fig. 7A) whereas nematode numbers and distribution within the circle exposed to $\mathrm{CO}_{2}$ did not noticeably change during the $24 \mathrm{~h}$. The $\mathrm{pH}$ of the $\mathrm{CO}_{2}$ exposed area was measured as 5.0-5.3, depending on position tested, and the $\mathrm{pH}$ outside the circle area was about 6.0. When delivery of $\mathrm{CO}_{2}$ was stopped after $24 \mathrm{~h}$, and the plate was examined at $48 \mathrm{~h}$, nematodes were found to have aggregated within the circular area. At this time, the $\mathrm{pH}$ inside the circle was around 5.6, whereas that outside was around 6.0. This experiment was repeated four times with similar results. In a shorter time course, delivery of $\mathrm{CO}_{2}$ was stopped after $4 \mathrm{~h}$, and plates were observed at $24 \mathrm{~h}$. In this experiment also, nematodes aggregated around the circle while $\mathrm{CO}_{2}$ 

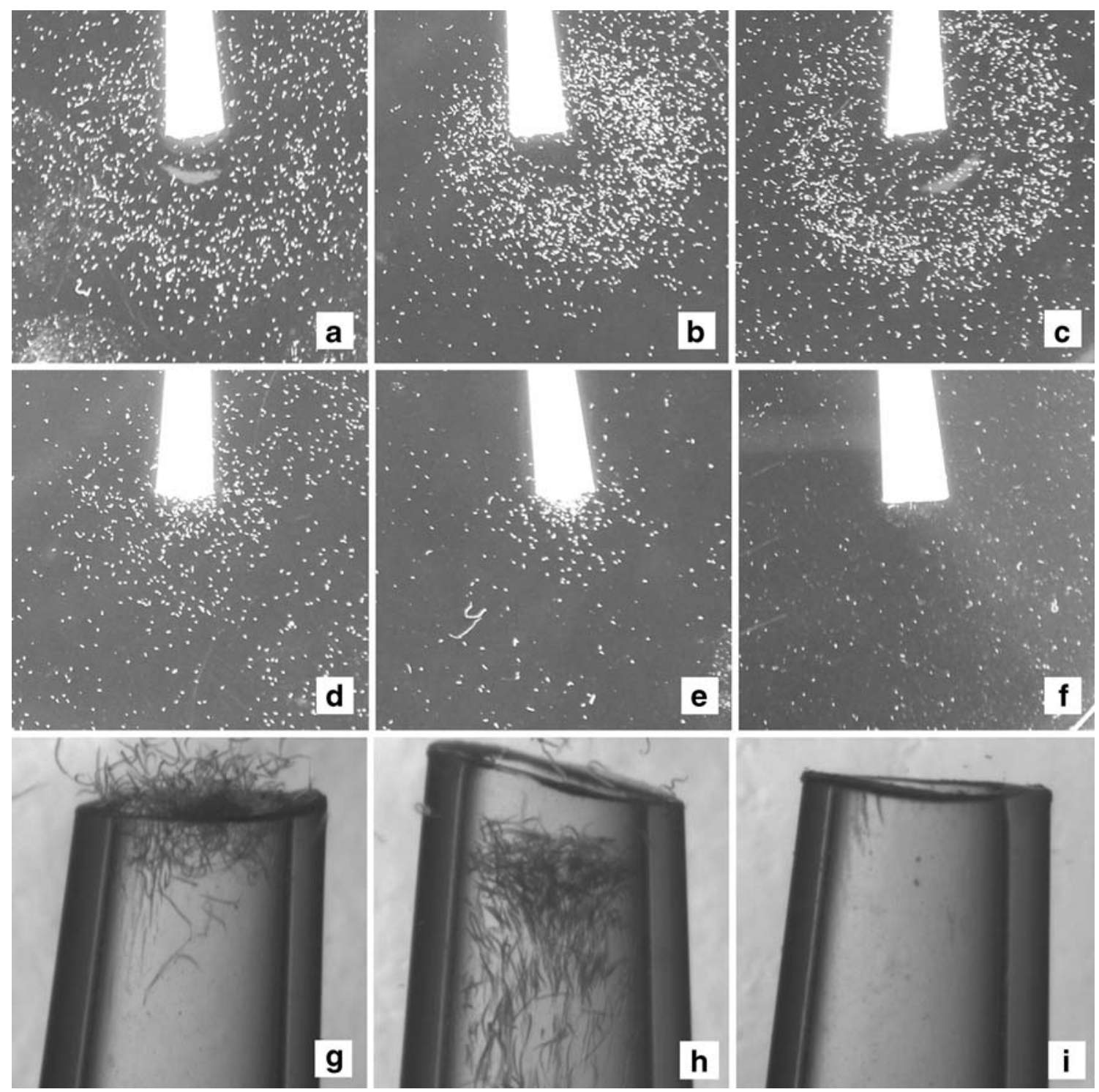

Fig. 5 Response of Meloidogyne hapla VW9 J2 to acid gradients in PF-127 gel. Each assay was in a Petri dish containing $6000 \mathrm{~J} 2$ in $20 \mathrm{ml}$ of gel in $10 \mathrm{mM}$ Tris-MES, pH7. Dispensers contained $0.40 \mathrm{M}$ solutions of $\mathrm{HCl}(\mathbf{A})$, propionic acid $(\mathbf{B}, \mathbf{G})$, methane sulfonic acid (C), or pyridinium methanesulfonic acid (E), or $0.16 \mathrm{M}$ citric acid (D,

was delivered, then moved inside during the next $24 \mathrm{~h}$ after the source of $\mathrm{CO}_{2}$ was disconnected. At the latter time the $\mathrm{pH}$ inside the circle was $\sim 5.8$ whereas that outside was $\sim 6.1$.

To distinguish the response to $\mathrm{CO}_{2}$ from that of reduced $\mathrm{pH}$, the $\mathrm{CO}_{2}$ experiment was repeated with gel buffered with $10 \mathrm{mM}$ sodium acetate, $\mathrm{pH}$ 4.9. At $24 \mathrm{~h}$ after continuous $\mathrm{CO}_{2}$ exposure, nematodes remained uniformly distributed throughout the gel and did not aggregate at the border of the circle (Fig. 7B). Using a microelectrode, the $\mathrm{pH}$ inside the circle was determined to be approximately 4.7 and that in the surrounding gel 4.9. At $24 \mathrm{~h}$ after removal of the $\mathrm{CO}_{2}$ source, nematodes aggregated within
$\mathbf{H})$, or water (F,I). All photographs were taken at $20 \mathrm{~h}$ after insertion of the dispensers. Panels A-F show the large end of the dispenser and were taken with edge lighting against a black background. Panels G-I show small opening of dispenser, and photomicrographs were taken under a dissecting microscope

the circle but to a much lesser extent than when the gel was buffered at $\mathrm{pH}$ 7.0.

\section{Discussion}

All tested strains of RKN J2 aggregated in a gel zone with a $\mathrm{pH}$ range of 4.5-5.4, e.g., from an acetic acid gradient. These species, as well as many other plant pathogens/symbionts, are strongly attracted to and invade roots in the zone of elongation. Growing root cells extrude protons, with the elongation zone being the most acidic region (Mulkey and Evans 1981; Pilet et 
Table 1 Attraction to acetic acid of species and strains of root-knot nematode ${ }^{\mathrm{a}}$

\begin{tabular}{|c|c|c|c|}
\hline \multirow[t]{2}{*}{ Species/ Strain } & \multirow[t]{2}{*}{ Isolate host and location } & \multicolumn{2}{|c|}{ Nematodes within $5 \mathrm{~mm}$ of tip } \\
\hline & & $3 \mathrm{~h}$ & $24 \mathrm{~h}$ \\
\hline \multicolumn{4}{|c|}{ Meloidogyne hapla } \\
\hline VW9 & Tomato, CA & $106.8 \mathrm{~A}$ & +++ \\
\hline NCS & Unknown, NC & $62.8 \mathrm{~B}$ & ++ \\
\hline LM & Unknown, France & $71.5 \mathrm{~B}$ & ++ \\
\hline \multicolumn{4}{|l|}{ M. javanica } \\
\hline VW4 & Unknown, CA & $57.0 \mathrm{BC}$ & + \\
\hline VW5 & Unknown, CA & $50.5 \mathrm{C}$ & + \\
\hline \multicolumn{4}{|l|}{ M. incognita } \\
\hline VW6 & Cotton, CA & $26.8 \mathrm{D}$ & $57 \mathrm{~A}$ \\
\hline Beltran & Lima bean, $\mathrm{CA}$ & $37.0 \mathrm{D}$ & $73 \mathrm{~A}$ \\
\hline Harmony & Grape, CA & $4.5 \mathrm{E}$ & $30.5 \mathrm{~B}$ \\
\hline $557 \mathrm{R}$ & Tomato, NC & $58.8 \mathrm{BC}$ & ++ \\
\hline W1 & Tomato, CA & $28.8 \mathrm{D}$ & $81.0 \mathrm{~A}$ \\
\hline
\end{tabular}

\begin{abstract}
${ }^{a}$ Two chemical dispensers filled with $0.17 \mathrm{M}$ acetic acid were used for each plate and three plates for each treatment. At the indicated time after insertion of the dispensers, the number of nematodes within the $5 \mathrm{~mm}$ diam. circle, centered at the small end of pipette tip, was counted. The counts were corrected by subtracting similarly counted nematode numbers for dispensers containing gel alone. Significant differences between counts on different nematode strains at the $3 \mathrm{~h}$ time point are indicated with letters A-E $(P<0.05)$. Nematodes continued to aggregate so that counts were not possible at $24 \mathrm{~h}$ for some trials, but relative nematode densities were assigned symbols + , ++ , and +++ following the examples in Fig. 6. For the four strains whose numbers were assessed at the $24 \mathrm{~h}$ time point, significant differences are indicated by letters A and B $(P<0.05)$.
\end{abstract}

al. 1983; Peters and Felle 1999). Based on $\mathrm{pH}$ indicator dyes, this zone was found to be less than $\mathrm{pH} 5$ for maize seedlings grown on agar plates (Mulkey and Evans 1981). Using PF-127 gel and pH indicator dyes, we also found that Medicago truncatula and tomato seedlings produced an acid gradient around the root and could acidify the medium to $\mathrm{pH} 5$ or less immediately adjacent to the root (Wang and Williamson, unpublished). The correlation of the most acidic region of the root with that which is most attractive to the nematodes is consistent with the possibility that $\mathrm{pH}$ gradients are signals that direct nematodes to the elongation zone of growing roots. However, while low $\mathrm{pH}$ is a marker for the growth zone of a wide range of host plants, the influence of the growth zone on $\mathrm{pH}$ in the soil is likely much less than it is in water or gels (Nichol and
Silk 2001). In addition, we found that while the preferred $\mathrm{pH}$ range was the same for all root-knot nematode species tested, the rate of aggregation within the zone of preferred $\mathrm{pH}$ varied with the species and strains of root-knot nematode. Meloidogyne hapla VW9 aggregated most rapidly, whereas all M. incognita strains, except 577R, were significantly slower to aggregate than $M$. javanica and M. hapla species. These results cannot be reconciled directly with our previous observations of the relative migration rates of these same nematode species to host roots; i.e., movement of $M$. incognita and $M$. javanica J2 to tomato roots was much more rapid than that of $M$. hapla (Wang et al. 2009). Thus, $\mathrm{pH}$ is probably not the sole attractant to roots, and its relative importance may depend on the nematode strain as well as the host.
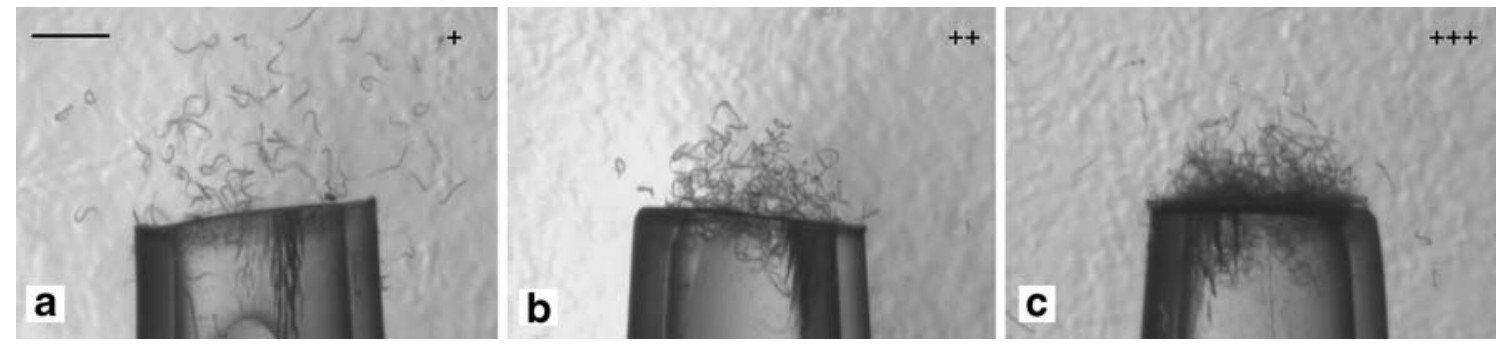

Fig. 6 Scoring aggregation of root-knot nematodes to acetic acid. The small opening of the dispenser with $170 \mathrm{mM}$ acetic acid is shown at $24 \mathrm{~h}$ after initiation of the assay. A. M. javanica strain VW4. This sample would be scored as "+" in Table 1. B. M. hapla strain LM. This sample was scored as "++." C. M. hapla VW9 was scored as "+++." Scale bar $=1 \mathrm{~mm}$ 


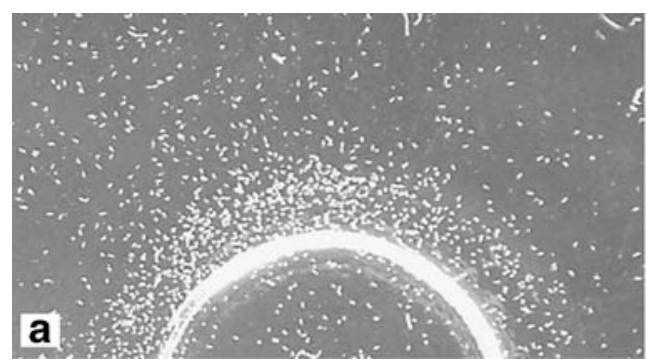

Fig. 7 Response of Meloidogyne hapla VW9 to $\mathrm{CO}_{2}$ in PF-127 gel. A. At $16 \mathrm{~h}$ after continuous exposure to $\mathrm{CO}_{2}$, nematodes aggregated just outside the area exposed to $\mathrm{CO}_{2}$ with pluronic gel buffered with $10 \mathrm{mM}$ Tris-MES, $\mathrm{pH}$ 7. B. No aggregation was observed when gel was buffered with sodium acetate, $\mathrm{pH}$ 4.9. At the start of the assay,

While all the acid solutions that we tested resulted in nematode aggregation, some appeared to be more attractive than others. For example, for citric, lactic, and succinic acids, nematodes migrated into the dispensers rather than forming a halo around the tip, suggesting that these acids may be specific attractants. In support of this, citrate salts with various cations at $\mathrm{pH}$ values of 4.5 or 5.5 also caused the nematodes to aggregate within the tip. Pyridinium hydrochloride and pyridinium methane sulfonate were tested because these Brønsted acids are similar to the tested carboxy acids in their acid gradient forming potential. However, the pyridinium salts proved to be strong attractants to RKN J2s; in agreement with this observation, pyridine has been reported to be an attractant for C. elegans (Dusenbery 1976). It is likely that nematodes respond to and integrate complex signals and/or combinations of signals in their natural environment and that perceived gradients may act in a synergistic or antagonistic manner. The assay described here has potential to identify and dissect some of these interactions.

Carbon dioxide has been widely reported to be an attractant to free-living, insect-parasitic and plant-parasitic nematodes (Pline and Dusenbery 1987; Robinson 1995; O'Halloran and Burnell 2003). However, some of these studies were carried out without buffers, and carbon dioxide can lower $\mathrm{pH}$ of aqueous solutions. In our assays, nematodes were attracted to just outside the $\mathrm{CO}_{2}$-permeated central cylinder (Fig. 1) when the gel was in $10 \mathrm{mM}$ TrisMES, pH 7.1 (Fig. 7A), whereas nematodes remained uniformly distributed throughout when the gel was buffered with $10 \mathrm{mM}$ sodium acetate, $\mathrm{pH} 4.9$ (Fig. 7B). A pH value of 4.9 was selected because it is within the $\mathrm{pH} 4.5$ to 5.4 range observed for the halos of nematodes that formed in acetic acid gradients (Fig. 3C) and because the calculated $\mathrm{pH}$ for water saturated with $\mathrm{CO}_{2}$ is 4.4 . That is, when the initial $\mathrm{pH}$ is 4.9 , little perturbation of the gel $\mathrm{pH}$ is expected from introduction of $\mathrm{CO}_{2}$; our gel $\mathrm{pH}$ measurements agreed with this expectation. Thus, for the $\mathrm{pH} 7.0$ gel assay, it is

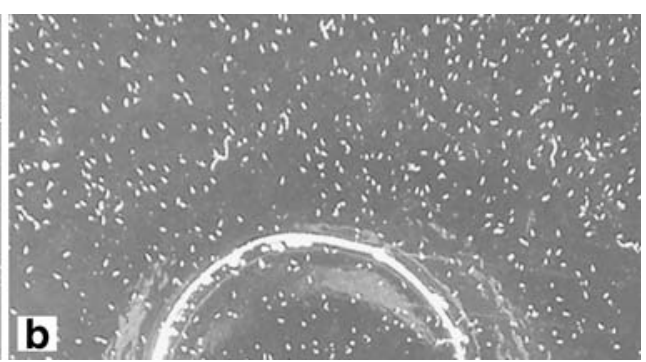

$9000 \mathrm{~J} 2$ were dispersed in $30 \mathrm{ml} \mathrm{PF}-127$ and poured into the Petri dish. The images show an arc of the $1.5-\mathrm{cm}$ diameter circle that was exposed to $\mathrm{CO}_{2}$. Note that the number of $\mathrm{J} 2$ inside the circle is similar in $\mathrm{A}$ and $\mathrm{B}$

likely that what attracted $\mathrm{J} 2$ to the region around the central cylinder was a $\mathrm{pH}$ gradient, not $\mathrm{CO}_{2}$.

For either $\mathrm{pH} 7.0$ or 4.9 , the number of nematodes in the central cylinder of gel did not change in number while the cylinder was continuously exposed to $\mathrm{CO}_{2}$. However, nematodes entered this area after the delivery of $\mathrm{CO}_{2}$ was terminated. There are several possible explanations for the failure of the nematodes to enter the $\mathrm{CO}_{2}$-exposed region. $\mathrm{CO}_{2}$ is an anesthetic, and concentrations of $\mathrm{CO}_{2}$ above $10 \%$ have been reported to cause a decrease in movement for $M$. incognita (Pline and Dusenbery 1987). Thus, perhaps the nematodes regained ability to move into the central region once the level of the dissolved gas had decreased sufficiently. Our $\mathrm{pH}$ measurements indicate that the $\mathrm{pH}$ remained lower in the central region compared to the periphery, possibly contributing to the attraction. In addition, it is likely that the oxygen level was lower in the region exposed to $\mathrm{CO}_{2}$, and root knot nematodes may prefer less than ambient oxygen levels as does C. elegans (Gray et al. 2004). As with any in vitro assay, caution should be used in extrapolating in vitro experiments with more complex soil conditions. However, this system has the potential to provide new insights into nematode behavior in natural soil.

The method of dispenser immersion in PF-127 gel described here is simple in design and execution, and it produced steady-state $\mathrm{pH}$ gradients in which nematode movement was easy to visualize and document over time. Results were reproducible enough in both nematode distribution and maximum density, so that data from several plates could be combined and presented as a close approximation to a normal distribution of $\mathrm{J} 2$ density vs. distance from the dispenser end (Fig. 4). This system has advantages over agarose-based methods in which the test chemical is applied to a well in the agar (Wuyts et al. 2006) or on the surface of the gel (Ward 1973; Matsuura et al. 2007) to form a gradient. For agar-based assays, the volume of test substance that can be applied is limited, and sometimes a second application is needed to maintain the 
gradient, whereas with our system the dispensers provided an ample reservoir of test chemical. The PF-127 assay medium in which nematodes are dispersed is threedimensional. Therefore, the nematode is not constrained to orientations that may be sub-optimal for perception of chemical gradients by amphids and can move in any direction in response to a detected gradient. Photographs with edge lighting allowed population scale analyses of nematode behavior in response to chemical stimuli, although nematode entry into the dispensers was obscured. Under the microscope, local gatherings of nematodes, in the dispenser and elsewhere, were observed, and the clarity of the PF-127 gel allowed the examination of the behavior of individual nematodes.

Assays of this type have great potential for chemotaxisresponse studies with a variety of potentially attracting substances, including root tissues (Wang et al. 2009) or small organisms, and should be suited for the study of the responses of a variety of small invertebrates, fungal zoospores, and other subjects.

Acknowledgements We thank Howard Ferris for comments on the manuscript. This project was supported by the National Research Initiative of the USDA Cooperative State Research, Education and Extension Service, grant number \# 566000756 and by the Agricultural Experiment Station of the University of California.

Open Access This article is distributed under the terms of the Creative Commons Attribution Noncommercial License which permits any noncommercial use, distribution, and reproduction in any medium, provided the original author(s) and source are credited.

\section{References}

Abad, P., Gouzy, J., Aury, J. M., CASTAGnONE-SEREnO, P., DANChin, E. G., Deleury, E., Perfus-Barbeoch, L., Anthouard, V., Artiguenave, F., BloK, V. C., Caillaud, M. C., Coutinho, P. M., Dasilva, C., De Luca, F., Deau, F., Esquibet, M., Flutre, T., Goldstone, J. V., Hamamouch, N., Hewezi, T., JaIllon, O., Jubin, C., Leonetti, P., Magliano, M., Maier, T. R., Markov, G. V., McVeigh, P., Pesole, G., Poulain, J., RobinsonRechavi, M., Sallet, E., Segurens, B., Steinbach, D., Tytgat, T., Ugarte, E., Van Ghelder, C., Veronico, P., Baum, T. J., BlaXter, M., Bleve-Zacheo, T., Davis, E. L., Ewbank, J. J., FAVERY, B., Grenier, E., HENRISSAT, B., JONES, J. T., LAUDET, V., Maule, A. G., Quesneville, H., Rosso, M.N., Schiex, T., SMant, G., Weissenbach, J., and WincKeR, P. 2008. Genome sequence of the metazoan plant-parasitic nematode Meloidogyne incognita. Nature Biotechnol. 8:909-915.

BIRD, A. F. 1960. Additional notes on the attractiveness of roots to plant parasitic nematodes. Nematologica 5:217.

Branch, C., Hwang, C. F., Navarre, D. A., and Williamson, V. M. 2004. Salicylic acid is part of the Mi-1-mediated defense response to root-knot nematode in tomato. Mol. Plant-Microbe Interactions 17:351-356.

Bretscher, A. J., Busch, K. E., and De BonO, M. 2008. A carbon dioxide avoidance behavior is integrated with responses to ambient oxygen and food in Caenorhabditis elegans. Proc. Natl. Acad. Sci. USA 105:8044-8049.
Castro, C. E., McKinney, H. E., and LuX, S. 1991. Plant protection with inorganic ions. J. Nematol. 23:409-413.

Chen, P., and RoberTs, P. A. 2003. Virulence in Meloidogyne hapla differentiated by resistance in common bean (Phaseolus vulgaris). Nematology 5:39-47.

DusEnBERY, D. B. 1976. Attraction of nematode Caenorhabiditis to pyridine. Comp. Biochem.Physiol. C-Pharmacol. Toxicol. \& Endocrinol. 53:1-2.

DusEnBERY, D. B. 1983. Chemotactic behavior of nematodes. $J$. Nematol. 15:168-173.

GARDENER, S. and JONES, J. G. 1984. A new solidifying agent for culture media which liquefies on cooling. J. Gen. Microbiol. 130:731-733.

Gleason, C. A., LiU, Q., and Williamson, V. M. 2008. Silencing a candidate nematode effector gene corresponding to the tomato resistance gene Mi-1 leads to acquisition of virulence. Mol. Plant-Microbe Interactions 21:576-585.

Gray, J. M., Karow, D. S., Lu, H., Chang, A. J., Chang, J. S., Ellis, R. E., Marletta, M. A., and BargmanN, C. I. 2004. Oxygen sensation and social feeding mediated by a C. elegans guanylate cyclase homologue. Nature 430:317-322.

Hallem, E. A., and STernBerg, P. W. 2008. Acute carbon dioxide avoidance in Caenorhabditis elegans. Proc. Natl. Acad. Sci. USA 105:8038-43.

KLINGLER, J. 1965. On the orientation of plant nematodes and of some other soil animals. Nematologica 11:4-18.

Ko, M. P., and VAN GUNDY, S. D. 1988. An alternative gelling agent for culture and studies of nematodes, bacteria, fungi, and plant tissues. J. Nematol. 20:478-485.

LINFORD, B. M. 1939. Attractiveness of roots and excised shoot tissues to certain nematodes. Proc. Helm. Soc. Wash. 6:11-18.

LIU, Q. L., and WiLLIAMSON, V. M. 2006. Host-specific pathogenecity and genome differences between inbred strains of Meoloidogyne hapla. J. Nematol. 38:158-164.

MatsuURA, T., ENDO, S., IWAMOto, R., TAKAHAShi, H., and ICINOSE, M. 2007. Developmental changes in chemotactic response and choice of two attractants, sodium acetate and diacetyl, in the nematode Caenorhabditis elegans. Comp. Biochem. Physiol. A Mol. Integr. Physiol. 147:920-927.

MulKeY, T. J., and Evans, M. L. 1981. Geotropism in corn roots: evidence for its mediation by differential acid efflux. Science 212:70-71.

NiCHOL, S. A., and SILK, W. K. 2001. Empirical evidence of a convection-diffusion model for $\mathrm{pH}$ patterns in the rhizospheres of root tips. Plant, Cell \& Environ. 24:967-974.

O'HALloran, D. M., and Burnell, A. M. 2003. An investigation of chemotaxis in the insect parasitic nematode Heterorhabditis bacteriophora. Parasitology 127:3375-385.

OpPerman, C. H., BirD, D. M., Williamson, V. M., RoKHSAR, D. S., Burke, M., Cohn, J., Cromer, J., Diener, S., Gajan, J., Graham, S., HoufeK, T. D., LiU, Q., Mitros, T., Schaff, J., SCHAFFER, R., SCHOLl, E., SOSINSKI, B. R., ThOMAS, V. P., and Windham, E. 2008. Sequence and genetic map of Meloidogyne hapla: A compact nematode genome for plant parasitism. Proc. Natl. Acad. Sci. USA 105:14802-14807.

Perry, R. N. 2005. An evaluation of types of attractants enabling plant-parasitic nematodes to locate plant roots. Russ. J. Nematol. 13:83-88.

Peters, W. S. and Felle, H. H. 1999. The correlation of profiles of surface $\mathrm{pH}$ and elongation growth in maize roots. Plant Physiol. 121:905-912.

Pilet, P. E., Versel, J., and Mayor, G. 1983. Growth distribution and surface pH patterns along maize roots. Planta 158:398-402.

Pline, M. and DusEnBERY, D. B. 1987. Responses of plant-parasitic nematode Meloidogyne incognita to carbon dioxide determined by video camera-computer tracking. J. Chem. Ecol. 13:873-888. 
PROT, J. C. 1980. Migration of plant parasitic nematodes towards plant roots. Rev. Nématol. 3:305-18.

RIDDLE, D. L. and BIRD, A. F. 1985. Responses of the plant parasitic nematodes Rotylenchulus reniformis, Anguina agrostis and Meloidogyne javanica to chemical attractants. Parasitology 91:185-195.

RoBINSON, A. F. 1995. Optimal release rates for attracting Meloidogyne incognita, Rotylenchulus reniformis, and other nematodes to carbon dioxide in sand. J. Nematol. 27:42-50.

SPence, K. O., LewIS, E. E., and PerRY, R. N. 2008. Host-finding and invasion by entomopathogenic and plant-parasitic nematodes: evaluating the ability of laboratory bioassays to predict field results. J. Nematol. 40:93-98.

Wang, C., Lower, S., and Williamson, V. M. 2009. Application of pluronic gel to the study of root-knot nematode behavior. Nematology 11:453-464.
WARD, S. 1973. Chemotaxis by nematode Caenorhabditis elegans: identification of attractants and analysis of response by use of mutants. Proc. Natl. Acad. Sci. USA 70:817-821

Wuyts, N., Swennen, R., and Waele, D. D. 2006. Effects of plant phenylpropanoid pathway products and selected terpenoids and alkaloids on the behaviour of the plant-parasitic nematodes Radopholus similis, Pratylenchus penetrans and Meloidogyne incognita. Nematology 8:89-101.

Wyss, U., GrundLER, F. M. W., and Munch, A. 1992. The parasitic behaviour of second stage juveniles of Meloidogyne incognita in roots of Arabidopsis thaliana. Nematologica 38:98-111.

Yaghoobi, J., Yates, J. L., and Williamson, V. M. 2005. Fine mapping of the nematode resistance gene Mi-3 in Solanum peruvianum and construction of a $S$. lycopersicum DNA contig spanning the locus. Mol. Genet. Genom. 274:60-69. 